\title{
VINTAGE online tool for self eValuatIoN of key competences in adulT AGE" - Frame and evidences
}

\author{
Laura Vettraino $^{1}$, Jaap van Lakerveld ${ }^{2}$, Anne Berger ${ }^{3}$, Eleonora Guglielman ${ }^{1}$, Anja Zonneveld ${ }^{2}$ \\ Learning Community ${ }^{1}$ \\ PLATO $^{2}$ \\ Wisamar $^{3}$
}

\begin{abstract}
The paper presents the frame and evidences of the GRUNDTVIG Project VINTAGE, an European Project aimed at developing an online digital tool for self evaluation of key competences in Adult age, funded by the Lifelong Learning Programme (Reference: 527349-LLP-1-2012-1-ITGRUNDTVIG-GMP- Grant Agreement n. n. 20124192/001-001). The "Status artis" research of the European background of existing strategies and approaches for the assessment and self-assessment of competences in adult education, offers the starting point. The research report inspires a methodological framework, based on a self-reflective pathway, offering a procedure to guide adult learners in the self-assessment of key competences. Once tested and improved, this framework offered the base for the implementation of an online digital tool for a guided process of self-evaluation of key competences, easy to use, aimed to be enacted also without the support of evaluation experts. The authors of this paper present here the main achieved results, yet the whole partnership is the collective author and owner of the project outputs. Anja Zonneveld and Jaap van Lakerveld in this paper are the owner of the Reasearch results presentation, Anne Berger is the owner of the methodological framework description and self-evaluation procedure presentation. Laura Vettraino and Eleonora Guglielman curated the remaining sections valorizing the contributions from all VINTAGE project partners.
\end{abstract}

\section{Introduction}

Rapid societal changes, the increasing pace of knowledge production, shifting positions of nations and continents in international competition, demographic changes, technological changes, youth unemployment and ageing population are just a few of the developments that led the European Commission and other policy making bodies to emphasize the necessity of lifelong learning in a wide variety of fields of work.

The European parliament, the European Commission and the Council of Europe agree on the importance of eight key competences for lifelong learning. The European framework for key competences for lifelong learning identifies and defines eight key competences necessary for personal fulfilment, active citizenship, social inclusion and employability in a knowledge society [1]:

1. Communication in the mother tongue;

2. Communication in foreign languages;

3. Mathematical competence and basic competences in science and technology;

4. Digital competence;

5. Learning to learn;

6. Social and civic competences;

7. Sense of initiative and entrepreneurship;

8. Cultural awareness and expression.

With the support of European Commission (EACEA - Education, Audiovisual and Culture Executive Agency) a group of seven European Adult Educational Institutions and Educational Research Institutes form Italy, Sweden, Germany, Ireland, Austria, Netherlands, decided to contribute to the actuation of the European Policies for Adult learning by developing an online tool for self-assessment of key competences in adult education. Actually VINTAGE, that stands for "online tool for self eValuatIoN of key competences in adulT AGE" is an ongoing European project funded through Grundtvig Lifelong Learning Programme [2]. In order to meet this challenge the Project Partners realized a "Status artis" research describing the European background of existing strategies and approaches for the assessment and self-assessment of competences in adult education.

In this article we elaborate the concept of key competence in more detail and then turn to the issue of how to develop competences and what is more: how to assess them.

The "Status Artis" report on key competences in Adult education is a desk study focused on the acquisition and (self) assessment of key competences in adult education in Italy, Austria, Germany, Ireland, Netherlands and Sweden [3]. It is the starting point for the design of the VINTAGE selfevaluation framework that therefore is well founded in the analysis of literature, of other projects and practice examples in the field of Key Competence (KC).

The designed draft framework as been tested during seven parallel focus group sessions, in the six 
partner Countries, with experts and practitioners at European level. The results of this piloting, following explained, support the implementation of the online tool. A beta version of the online tool, mirroring the methodological framework, is already available for a piloting session, planned for Summer 2014. The final edition of the VINTAGE digital tool for self-assessment will be available by the end of 2014.

\section{Research on key competences: a source for an empirically based tool of self- assessment based on competence analysis}

The VINTAGE research on key competences allows to valorise and integrate previous European experiences and models, include the gathering and analysis of the existing European standards to recognize and record the competences, and the methods, practices and tools of assessment and evaluation.

We focus here on the findings most relevant for the development of the VINTAGE self-evaluation framework and the online tool.

\subsection{Key competence in Europe}

Several countries represented in VINTAGE have developed policy to stimulate lifelong learning like Italy, Austria, The Netherlands and Germany. In all countries initiatives can be found that address competence based adult education. In the projects found one or more of the $8 \mathrm{EU}$ key competences have the focus. Some Countries adopted the key competences of the EU, some use a different, but comparable set of competences. The adult target groups range from non-native citizens to working mothers and fathers to university students and teachers, those interested in further education and those returning to a job.

Competence based learning and assessment are used for study or other forms of professional development (career planning, reintegration on the Labour Market, study) or to personal development not related to work.

Actually it seems that the first main evidence of the research is that no previous approaches, projects or tools specifically developed for the selfassessment of Key Competences in adult education can be reported.

The first three competences indeed are linked with traditional school subjects and are integrated within the traditional national and school curricula.

Since European educational Systems are still mainly based on model of formal evaluation, focused on external judgment, it is common to find set of self assessment tests, also ICT based, mainly structured with objective items of assessment such us multiple choices or "fill in the blanks", in self evaluation of communication in mother tongue or in foreign languages, or of mathematical competences.

The competences of the second group, that are cross-curricular in nature are not included in institutional evaluation or self evaluation processes.

\subsection{Definition of Competence influences the evaluation}

The research also shows that a very common way of defining and assessing competences is to evaluate a person`s skills, knowledge and attitudes.

Competences as defined by educational experts throughout and beyond Europe, consist of three interrelated ingredients:

- a knowledge component (the understanding part),

- a behavioural components (the overt behavioural repertoire),

- a value component (including values, beliefs and attitudes).

The exact terminology differs from author to author. Competences consist of a combination of knowledge, skills and attitudes required for effective performance of a real-world task or activity. A competence is defined as the holistic synthesis of these components.

At another level a competence again may be divided in three components or aspects. It is the ability of a person to show:

- a particular behaviour in

- a particular context and with

- a particular quality.

These three aspects of competence comprise the actual ability of a person to perform. Cedefop defines competence as the ability to apply learning outcomes in a defined context [4]. This implies that what matters is not only what we know about things, but more important is what we are able to actually do with this knowledge: whether we show the desired competences in the context in which they are needed, how well we perform, and whether we are able to further develop our abilities. The question is: does education make learners knowledgeable, or does it make them competent? Below the components of competence are summarized in a model.

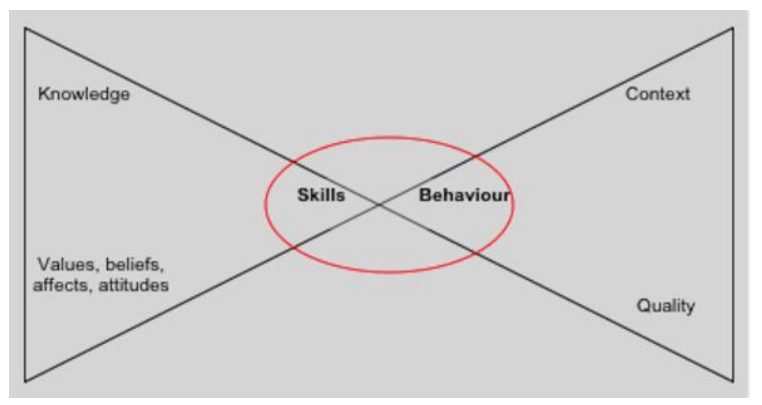

Figure 1. The components of competence 
The ellipse in the middle of the scheme includes the actual performance that shows the level of control over a particular competence. The components in the left triangle (composing someone's potential) allow a person to show the intended behaviour in the right triangle. There the student demonstrates his/her acquired competence [5].

In traditional education the emphasis was on knowledge transfer mainly, so on the left triangle of the above presented model. In the actual constructivist approach of competence oriented learning and teaching, the focus is on contextual learning, active learning, productive learning and social/interactive learning. So the right triangle gets more attention. Quoting Clifford and Wilson, Imel states that constructive learning has the following characteristics [6]:

- it emphasizes problem solving;

- it recognises that learning and teaching take place in multiple contexts;

- $\quad$ it promotes self -regulated learning;

- it anchors teaching in the diverse life contexts of the learners;

- $\quad$ it encourages students to learn from each other;

- $\quad$ it employs authentic assessment [7].

The Vintage project also focus on the right triangle of the presented model above. This implies that the focus is on the learner's ability to actually perform. Along these lines of reasoning, the Vintage project sees it as its challenge to develop an online tool to help learners identify their actual competence and to assist them in finding appropriate evidence to make this competence tangible and visible to others.

\subsection{Tools, Approaches, Functions, Levels, Arrangements, Contexts, Users}

The proposed VINTAGE self-assessment framework moves from the just focused definition of competence and from the matrix analysis of the "Status artis report" that can be summarized in the following headings: Tools, Approaches, Functions, Levels, Arrangements, Contexts, Users.

This matrix served also as a source in the further process of developing the VINTAGE online tool that is a kind empirically based tool typology.

2.3.1. Tools. The tools found are self-assessment tools, group assessment tools (like 360 degrees feedback, benchmark activity in a group, individual or group interviews) or portfolio's containing several kinds of assessment instruments/activities, both in digital and papered version.

The list of tools actually provides a rich harvest of potential tools of various levels of sophistication and of social involvement. On the one hand we find simple kind of tests, checklists, questionnaires; on the other hand we see tools that involve group work and social interaction either face to face or on line. An interesting other dimension is the dimension of tools that focus on self-assessment, peer assessment, involvement of external observers or external assessors.

2.3.2. Approaches. Several approaches to assessment can be detected in the instruments:

- Biographical.

- Self-diagnostic.

- Diagnostic.

- Orientation (vocational)

- Learning.

- Evidencing.

- Guidance/coaching.

- Validation/certification (by an assessor).

- Networking/community.

- In-service learning.

- Appreciative approach.

- Career development /CV building.

2.3.3. Levels. In most tools there is no information available on levels of mastery, but in the cases in which there are, we see references to the EQF and national derivate of that [8]. We see also other attempts to create hierarchies of learning outcomes and ways to rate them.

2.3.4. Functions. The assessments described or mentioned in the national reports, show a variety of functions or purposes. The functions closely relate to the approaches described above. They may be summarised in the following way:

- Raising awareness of one's potential.

- Empowerment.

- Support in one's learning/development process (formative assessment).

- Providing evidence of competences and achievements.

- Summative assessment to identify learning outcomes.

- Validation.

- Certifications.

- Employability/mobility.

- Self-direction.

- Access to a country.

- Talent development.

- Career building.

- Evaluative assessment to provide educators with curricular feedback.

- Educative assessment Integrated within learning activities, educative assessment builds student's (and faculty's) insight in, and understandings their own learning and teaching. Assessment thus is a form of learning. 
2.3.5. Arrangements (settings and target groups). The assessment arrangements may be either:

- individual computer based tests, or arrangements involving peers,

- assessments involving assessors in the educational setting,

- assessors on the job,

- closed or open items of assessment in educative, work, Human Resource Development, and community settings at various levels of education,

- $\quad$ single events or trajectories involving various intensities of evidence (from answers to questions to in depth interviews or serious case studies etc.).

2.3.6. Users The following target groups may be recognized:

- Pupils/young adults in transfer from school to vocational training and/or from training into professional life/job.

- Students in the course of study or in transfer period towards work.

- Professionals in companies/schools/universities.

- Adult learners.

- Trainees.

- Returners to work.

- New citizens / migrants (civic integration programmes).

- Teachers.

Based on this empirical overview, the partners have identified the specifics of the Vintage selfevaluation procedure and of the online tool.

\section{The VINTAGE framework and the self evaluation procedure}

Based on the research findings and presented competence definition Vintage project developed a Framework of self-evaluation presenting procedure, including mastery levels, assessment items, quality questions and competence profile. An interlinked basic Vintage portfolio gives the opportunity to document and collect personal experiences of key competence acquisition and development.

The Vintage self-assessment approach aims to self-evaluate the performance in a certain key competence, trying for an innovative alternative to common knowledge based multiple-choice questionnaires to evaluate competences. It assigns an active role to the user, calling upon reflective abilities, self-assessment competences and selfresponsibility. The procedure focuses on the Lifelong Learning approach, aiming to offer a tool for personal empowerment and development, rather than for selective or solely professional purposes.
Vintage assessment framework focuses on actual behaviour a person is demonstrating in a realistic context, or rather a reconstruction of a realistic context (due to the preconditions of a self-assessment process through an online tool), in a particular situation and evaluating the quality of the performance. This chosen approach towards the assessment of learning outcomes and competences is as well supported by research that highlights the importance of the performance side in demonstrating (Key) Competence within the field of education and Lifelong learning.

Of course, the traditional tests were insufficient to evaluate a complex set of components. To be effective, the Vintage assessment set up and process assigns an active role to the user, calling on the user's responsibility and autonomy in an evaluation process that is based on self-reflective attitude. Engaging the user in such an active and responsible way additionally improves the self-assessment competences and aims at raising motivation of the adult learner and supporting the idea of selfdirectness of Lifelong learning. It is a process that requires involvement and participation by the user, and a good dose of reflection, bringing into play meta-competences typical of the self-assessment process and therefore particularly suited to an adult context.

\subsection{The Vintage self-assessment procedure - step by step}

Entering the Vintage online tool of selfassessment the user will go through a guided step by step process at the end of which one will be presented a key competence profile giving an overview on one's key competence performance, highlighting self-evaluation outcomes per competence domain and giving a general feedback on possible improvements.

At the beginning of the self-evaluation process there are a couple of choices to be made on the user's side, about which key competence, which key competence domain and on which level of mastery to assess. Not until then the actual process of selfassessment starts with evaluating the quality of personal key competence performances.

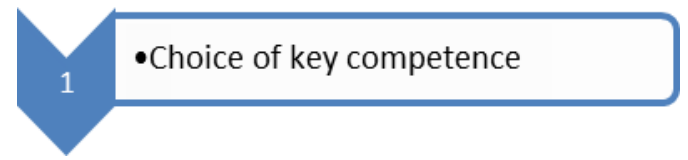

\section{Figure 2. First step of self assessment} procedure

The user, in a first step, is asked to choose, to start the self-assessment, one of key competence performance with, from the list of 8 key competences 
of Lifelong Learning named by the European Commission [2]:

1. Communication in mother tongue.

2. Communication in foreign language.

3. Mathematical competence and basic competence in science and technology.

4. Digital competence.

5. Learning to learn.

6. Social and civic competence.

7. Sense of initiative and entrepreneurship.

8. Cultural awareness and expression.

An easy guide offers information about the $8 \mathrm{key}$ competences of Lifelong learning and supports the user's choice. An additional contextual text guidance gives support and information throughout the whole process.

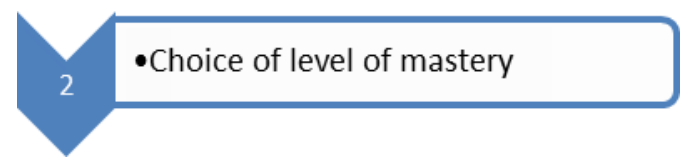

Figure 3. Second step of self assessment

In a next step five generic situations are presented, each one describing a situation in which the chosen key competence is performed in a common setting.

Each of the five situations corresponding to the following five levels of mastery:

- Level 1 can do when guided (in known situations),

- Level 2 can do, can choose (in known situations),

- Level 3 can combine, can design (also in unknown situations),

- Level 4 can improve, can extend,

- Level 5 can explain.

Throughout the EU a variety of different approaches on defining levels of mastery exist to rate learning outcomes, a person`s competences and abilities. One of the most widely known may be the EQF - European Qualification Framework for Lifelong Learning published by the EU in 2008 with eight levels of mastery, while national implementations of this Framework and other approaches in the field of evaluation of (key) competences refer to variety of different levels to rank competences acquisition [8]. Vintage selfassessment framework decided for 5 levels of mastery, referring to common settings in education, lifelong learning approaches and competence acquisition [9].

The user is given the opportunity to choose the Mastery level he/she feels most comfortable with when starting the self-assessment procedure and will then go on to the next stage.

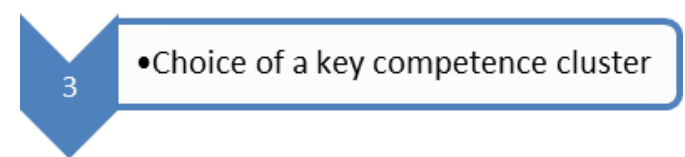

Figure 4. Third step of self assessment

Five different domains of the chosen key competence are presented. These domains are well grounded in Vintage research considering projects and publications throughout European countries, subdividing each key competence in a catalogue of sub-competences considered to be homogeneous parts, forming the overall picture of each key competence [3].

After deciding for a domain the user is presented a situation in which the key competence in the chosen domain is performed. Like before in the generic situations, these are meant to be broad enough to apply to many common experiences, yet specific enough to identify what a performance in a certain key competence and domain requires. They are meant to refer to daily life settings, supporting the user in his/her reflective abilities to relate own experiences and performances to the described situations.

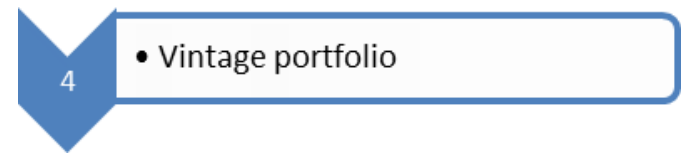

Figure 5. Fourth step of self assessment

An interlinked feature of the online tool offers the opportunity to note and reflect upon own experiences and collect these in the Vintage portfolio as documentation of personal key competence experiences to be used in further development or to be included in e.g. the European Curriculum Vitae Europass format [10].

The Vintage approach is focusing on the personal experiences of key competence performances throughout all areas of life, be it in family, educational, professional and leisure time settings.

It trusts upon the ability of the user to recall situations that occurred in his/her life that can be related to the provided situations involving described tasks and required indicated skills, knowledge and attitudes. Amongst others this stresses the importance and relevance of lifelong learning, be it in formal, non-formal or in-formal settings. The performance of key competences is not exclusively located in professional or job related settings.

After deciding for a key competence, a level of mastery and a domain the actual self-assessment of the user starts with self-evaluating the quality of recalled performances in the chosen key competence and domain. 
5

- Rating the quality of key competence performances

\section{Figure 6. Fifth step of self assessment}

The quality of the performance is, consequently to the premises of self-assessment, evaluated by the user himself, ranking personal performances on the following four dimensions of qualities:

$\begin{array}{ll}\text { 1. } & \text { Reflective } \\ \text { 2. } & \text { Autonomous } \\ \text { 3. } & \text { Self-directed - Self-regulated } \\ \text { 4. } & \text { Effective }\end{array}$

The four quality dimensions thereby refer to themes such as critical thinking, creativity, initiative, problem solving, risk assessment, decision-taking and constructive management of feelings. These are considered to play an important role in all 8 key competences according to The European framework for key competences for lifelong learning published by the European Commission in 2007 [1].

Corresponding sets of control questions per quality dimension have to be ranked on a scale from 1 (basic) to 5 (very good) in order to estimate personal performance of a certain cluster and key competence.

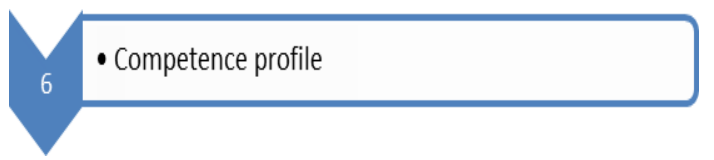

\section{Figure 7. Sixth step of self assessment}

The same procedure must be repeated for each domain of the competence, which should be all evaluated to obtain a complete result. The output of the self-assessment process of each competence is the description of the competence profile, resulting from the combination of the level of mastery and the quality rate expressed for all competence clusters. This self-assessment model is grounded on the approach of self-diagnosis in the contest of adult education and reverses the traditional evaluation pathway: the adult learner is asked to recognize himself in a profile, activating self-reflection and self-direction capabilities. This recognition is the starting point to carry out the self-assessment process, and to acquire awareness to draw a selfportrait that fully represents the person and the possessed competences.

\section{The test bench}

The designed framework and procedure of self evaluation as been tested through seven parallel focus group sessions, in the six partner Countries, involving European experts and practitioners.
The aim of the Focus group was to test and gather information useful in order to fine tune the Vintage framework.

The observations emerged during the focus group sessions provided suggestions and recommendations on how to adjust the self-evaluation procedure in order to make them more effective and to try to reach the wider possible range of target groups, as well as to gather a general opinion on their usefulness and employability in adult education.

Between the months of December 2013 and February 2014, each Project partner realized a focus group session in its Country. Experts were sent information materials, namely a presentation of the self-evaluation procedure developed by the Vintage project together with the frameworks of Key Competence 2 "Communication in foreign languages" and Key Competence 4 "Digital competence", and were invited to analyse them, to try to experiment the procedure and finally to take part to the focus group session in order to discuss, openly and clearly, all relevant aspects of the VINTAGE framework: point of strengths, weaknesses, possible changes, possible use within adult education.

The focus group sessions involved 58 experts/practitioners:

- 7 from Austria,

- 8 from Germany,

- 6 from Ireland,

- 22 from Italy,

- 6 from the Netherlands,

- 9 from Sweden.

All focus group sessions were organized by paying great attention in trying to have the wider possible variety of participants in terms of roles and positions covered within the field of adult education. Among the participants it is possible to notice a prevalence of researchers, teachers and practitioners although significant is also the presence of people organizing and making decisions on various activities of adult education, with 28 males and 30 females, with qualifications corresponding to tertiary and higher education.

All the participants have received information material about VINTAGE and the link to the website in order to read, download and analyse the outputs of the Project. Together with the invitation to the Focus group sessions, they have also received a presentation of the self-assessment procedure, a guide to test the procedure and the frameworks of two $\mathrm{KCs}$ as a sample (KC2 and $\mathrm{KC} 4)$.

Participants were asked to express and discuss their opinions on the general structure of the selfevaluation framework, to test on themselves the procedure and to study analytically two main questions:

- instructions and self-evaluation procedure; 
- possible use of the Vintage tool in Adult Education.

To enlarge the geographical and target impact, involving practitioners and experts in the piloting also at a distance, a web survey has been realized. It consisted in a questionnaire of ten questions complementary to the focus group guide, published on the web, using a free tool (surveymonkey.com). Approximately 70 people returned back the web survey.

\subsection{Main highlights}

An important premise to be noted is that despite the variety of the positions covered by the participants, their experiences in the field of adult education and their national background, the opinions emerged during the discussions and collected in the different local reports and web survey are generally the same for all partner Countries. So, apart from some minor references to specific local situations or target groups, we can say that the observations and provided remarks can be considered valid, unbiased and reflecting a common feeling on the procedure developed by the Vintage project.

It is important to underline the opinions expressed by the participants to the Focus group sessions on the Vintage project, particularly on its theoretical structure and on its aims.

To this respect the evaluation is very positive. Most of the participants in the different national contexts agree that the theoretical structure (namely the concepts of competence and self evaluation) are central and of the utmost importance in adult education. The observations and remarks expressed can be summarized in four points:

1. Tools and instruments promoting and fostering self-evaluation among adult people are necessary and highly valuable because whatever kind of learning in adult age has its origin in a process of self-evaluation. This is the process bringing adult individuals to raise awareness of their training/education needs, it brings about their interest towards learning and it is at the basis of their decision to (re-)enter a learning route. For these reasons, the attempt carried out by the Vintage project to develop and define a procedure of self-evaluation on Key Competences, to test it and verify its possible use is important and useful.

2. An effective self-evaluation procedure, such as the Vintage project is trying to develop, cannot consist in a range of tests aimed at measuring knowledge but it should have the ambition to build a guided process of reflection, whose central figure is the adult person.

3. In the perspective of such process of reflection, participants consider appropriate the choices made at the beginning of the project: analysing competences focusing on Contexts and Behaviours; requesting the adult users to evaluate their own performed behaviours in real life situations through quality indicators.

4. A self-evaluation tool presenting features such as those of the Vintage project demands a very complex procedure and requires adult users an investment in terms of time and attention.

Starting from these general remarks, however, it is important to notice that a common concern is that such choices lead to a tool whose operating procedure is very complex and that requires the potential user a strong commitment in terms of time and attention/concentration.

From this consideration originates the prevalent opinion expressed by the participants to the focus group realized in the countries of the partnership: the Vintage procedure, more than a tool to be used individually, can work as a useful and important methodological instrument to be used in the various typical contexts of adult education (defining a personal development plan, (re-entering the Labour Market, etc.). In particular, it would be useful in a training context involving small groups (one trainer and 3-4 learners).

From this observation comes the suggestion of producing a handbook/guide for teachers explaining how to use the tool, also in a training environment.

Moreover, the focus groups provided some precious suggestions and recommendation for the implementation of the online tool aimed at overcoming (as much as possible) the complexity of the procedure. In order to allow a wider and successful access to the VINTAGE tool, including also adults with low level of education or low skilled, it is necessary to reduce the length of texts, simplify the language and use images and illustrations. These measures would allow a fuller understanding of the steps and actions required to the user undergoing the self-evaluation procedure.

With reference to the description of performed behaviours in real life situations evoked through the suggested items, it is commonly asked to provide a guide for the description of the situation and the reconstruction of the performed behaviours. The user should be given detailed information on the best ways to describe and analyse situations and behaviours.

It would be advisable to reduce the quality dimensions in relation to the chosen mastery level and the proposed item. In addition to this, it would be better to eliminate the titles of the quality dimensions while substituting them with control questions.

Finally, given the objective complexity of the procedure, the user should always have a clear perception of the progress achieved through the selfevaluation procedure. It would also be very 
important to give the users the possibility to leave the procedure at any given time and to re-enter it in a later moment to complete the process from where they left.

\subsection{Self evaluation procedure upgrading}

Taking advantage of these highlights some adjustments has been implemented to the selfevaluation procedure accordingly. The main improvements are here summarised:

- time management advices has been provided together with some key motivating messages about "Why to self assess";

- texts of the assessment items as been simplified;

- $\quad$ an Easy Guide has been developed, both papered and online;

- the adoption of the S.T.A.R. method (acronym of a behavioural interview technique standing for: Situation, Task, Action, Results) has been suggested to guide the actual performance recalling and reconstruction;

- the number of quality dimensions has been reduced from ten to 4, substituting abstract labels with guiding questions.

All these improvements has been integrated within the digital tool, guiding the user in the selfevaluation procedure step by step.

\section{The digital online self evaluation tool}

The VINTAGE digital tool for self evaluation of Key competences mirrors in a digital version the VINTAGE framework. A beta version of the online tool is already available for a usability test, planned for Summer 2014 to be basically held by adult learners from Italy, Germany, Austria, Ireland. The final edition of the VINTAGE digital tool for selfassessment, improved thanks to this second piloting, will be available by the end of 2014 .

The main components of the tool-related service are divided up in four parts:

- the Analysis part, where the assessment context is defined (Key competence, cluster, mastery level and the portfolio alternative used). This part also includes the quality dimension assessment of the defined performance for a given competence context.

- the Portfolio part, where the performance assessed in the specified competence context, and which can be documented online, off-line or retained in memory - undocumented.

- the Profiling part, where the feedback, reflections and/or recommendations are composed based on the competence context and the quality assessments made for the performance example(s) derived about this context. This is composed and presented with selective text paragraphs filtered in our out of a profiling report document.

- the Guidance part, where all explanations and instructions are provided as an online information service with chapters and subchapters/web-pages.

\subsection{The analysis part}

The online self-assessment tool is proposed to be operate as an interactive service with a sequence of pages/forms are presented to the user with requests for provision of replies and/or selections that defines the $\mathrm{KC}$ context that the self-assessment is going to by formatted for. Depending on the replies of the first set of questions/selections are a given variant of the next page displayed. Assessments are to be done for one Key Competence and cluster setting at the time, and pages are modified base on those initial $\mathrm{KC}$ context specifications. It is also made possible for user to go back to a previous page and change the earlier responses, and alternative pages may also be displayed as a result of such response changes. One cycle is collecting self-assessment data for one $\mathrm{KC}$ context. Up to $8 \mathrm{KCs}$ x 5 Competence Clusters + one overall $\mathrm{KC}$ per $8 \mathrm{KCs}=48$ contexts) is possible, as well as later re-visits to a given $\mathrm{KC}$ context, with possibility to revise the initially entered responses or selections. All replies stored in the assessment tool from a given user will subsequently also be used for the $\mathrm{KC}$ Profile generation with the profiling part of the Vintage KC self-assessment tool.

\subsection{The Key Competence Profiling service}

The proposed online KC Profiling service is intended to be constructed as an eBook where all chapters (one for each $\mathrm{KC}$ ), subchapters (e.g. competence domain), as well as all its separate content components / text paragraphs will be 'conditioned', i.e. displayed to an individual user depending on the replies, or reply-combinations that the user has selected/entered into the assessment tool for a given $\mathrm{KC}$ and competence cluster. There can be both general comments as well as reply-specific comments. No user will see the same eBook content. A user will also be able to make comments/reflections on the each part of the displayed profile components, and users will only see their own comments, even if also others have made their comments on the same profile component.

All the content components, or at least a majority of them, need to be defined and those include:

- general statements on each $\mathrm{KC}$, each domain, each master level, and quality levels,

- statements that are specific to a given $\mathrm{KC}$, and the clusters within it, the quality levels for it, and the respective quality levels for 
each competence context (i.e. $\mathrm{KC}$ and cluster combination);

- statements that are to be presented when a given response-combination occur, which also can be stated as a combination of AND/OR conditions for the text component's appearance.

In the proposed design of the online tool(s) for documenting the assessment of Key Competences at a given Mastery level that is intended to be part of the Vintage online self-assessment tool, three different modalities are accommodated:

- a WYSIWYG-based documentation facility, built-into the assessment tool itself. This documentation option will have capabilities both for importing content (text and graphics) into the documentation facility from Word files as well as catering for templates documentation templates;

- a interactive pre-formatted online application, separate from the assessment tool, with a preformatted structure into which content component can be added by the users, who will only see their own contributions, while application coordinators can review, and even comment, contributions by all users;

- a link option within the online assessment tool where users can provide a link to an external documentation/ePortfolio service.

\subsection{The Guidance part}

The online Guidance part is proposed to consist of a hierarchy of web pages including introductions/instructions and with menu lists taking the user to further details and back. Six main chapters is proposed to be included in this online guidance service/manual;

- Intro to Why to self assess.

- Intro to the assessment process and its different stages.

- Intro to the Key Competencies (KC) and its subordinate clusters.

- Intro to the Mastery Levels, and it interpretations for respective key competence and its associated competence clusters.

- Intro to the Quality Dimensions and possibly also the level interpretations in respective quality dimension.

- Intro to the portfolio/tool for documenting performance examples, possibly also including guide to difference portfolio documentation approached, and its use during quality assessments.

- Intro to KC Profiling part of the tool, including operational instructions and the process used to generate profile feedback, reflections and/or recommendations.
The online version of the Guidance also includes direct links to the other three parts of the Vintage assessment tool/service.

\section{Future perspectives}

Key Competences are often acquired and developed in non-formal and informal contexts; this makes them not assessed nor recognized and consequently not used by adults for their personal development and professional improvement. Some Countries are adapting school curricula in this sense, but there is still a big work to do in the field of adult education, especially about the strategies and method for the assessment of key competences. It lacks a culture of $\mathrm{KC}$, and their value is not enough valorised. This is confirmed by the European Council conclusions of 11 May 2010 on competences supporting lifelong learning and the 'new skills for new jobs' initiative, that invites to "Develop the Europass framework in line with the implementation of the EQF and with a view to recording and highlighting more effectively the knowledge, skills and competences acquired by citizens throughout their lives in a variety of learning settings, including by considering the development of a 'personal skills passport' based on existing Europass elements" [11]. Actually, for example, the Europass Curriculum Vitae format includes sections for the recording of Digital Competences, or Social competences, but differently from the description of foreign language competences, specific descriptors still lack for the description of these Key Competences. A great work has been done at a European level about the strategies and tools for assessing skill and competences; nevertheless, adult educational Systems are still mainly based on traditional models of external evaluation, assessment is often made by trainers and teachers on the basis of quantitative tests and assigned tasks. This is a critical point, since adult learners often refuse this kind of assessment, that they tend to associate to past school negative experience. This affects also the lack of motivation of adult learners to come back in the educational system, both in continuing education and NVAE pathways, as noted in the European Guide Lines for validating non formal and informal learning [12].

The self analysis of Key Competences can: help adult learners recognizing the possessed competences, making them transparent and measurable; the assessed competences can be recorded in the $\mathrm{CV}$, with the mastery level resulting after the self e-evaluation, and consequently they can be spent in learning pathways or in the labour market; a self-assessment tool, especially if userfriendly and disposable online, can be used autonomously by the adult learner, and can constitutes the first step of a more complex process, 
where the adult can choose to be helped by teachers and counsellors for further steps (e.g. the balance of competences); the VINTAGE framework, developed on the basis of European common standards, can be developed in direction of the validation of Key Competences.

These are the reasons why VINTAGE partners considered a good opportunity for the future to engage in the valorisation of the project results local representatives EUROPASS from Project partners' countries, where possible.

Moreover, the implementation and diffusion of a self-assessment culture, attitude and familiarity could represent a good opportunity to over cross adults' resistance and lack of motivation, and to give them real opportunities to develop and update their key competences throughout life.

Nevertheless Key Competences for Lifelong Learning concern all age ranges. Then, the perspectives offered by the technology supported learning could bring towards a development of the actual online tool into a mobile learning application easy and portable support for self evaluation everytime and every-where.

\section{References}

[1] European Commission, Key Competences for lifelong learning - European Reference Framework, Luxembourg: Office for Official Publications of the European Communities, 2007 http://ec.europa.eu/dgs/education_culture/publ/pdf/lllearning/keycomp_en.pdf

[2] http://vintage.euproject.org

[3] van Lakerveld J., Gussen I., de Zoete J., State of the art of Key competences and assessment in Europe, PLATO, Leiden, September 2013.

[4] Cedefop, Terminology of European Education and training Policy - a selection of hundred key words, Thessaloniki/Luxembourg, 2008.

[5] Lakerveld J., van \& Gussen I., Aqueduct - Acquiring Key Competences through Heritage Education, Landcommanderij Alden Biesen, Bilzen (Belgium), 2011.

[6] Clifford M., Wilson M., Contextual Teaching, Professional Learning, and Student Experiences: Lessons Learned from Implementation, Educational Brief n. 2, Madison: Center on Education and Work, University of Wisconsin-Madison, 2000.

[7] Imel S., Contextual learning in adult education, Practice application, brief n. 12, Madison: Center on Education and Work, University of Wisconsin-Madison, 2000.

[8] European Commission, Recommendation of the European Parliament and of the Council on the establishment of the European Qualifications Framework for lifelong learning, Luxembourg: Office for Official Publications of the European Communities, 2008.

[9] Gnahs D., Kompetenz - Erwerb, Erfassung, Instrumente, Bielefeld, 2010.

[10] Cedefop, European Commission, The European $C V$, 2004

https://europass.cedefop.europa.eu/de/documents/curriculu m-vitae

[11] European Council, Conclusions of 11 May 2010 on competences supporting lifelong learning and the "new skills for new jobs' initiative, (2010/C 135/03).

[12] CEDEFOP, European Guide Lines for validating non formal and informal learning, Luxembourg: Office for Official Publications of the European Communities, 2009. 